\title{
Investigation of Photolithography Process on SPOs for the ATHENA Mission
}

\author{
Massahi, S.; Girou, D. A.; Ferreira, D. D. M.; Christensen, F. E.; Jakobsen, A. C.; Shortt, B; Collon, M.;
} Landgraf, B.

\section{Published in:}

Proceedings of SPIE

Link to article, DOI:

$10.1117 / 12.2186810$

Publication date:

2015

Document Version

Publisher's PDF, also known as Version of record

Link back to DTU Orbit

Citation (APA):

Massahi, S., Girou, D. A., Ferreira, D. D. M., Christensen, F. E., Jakobsen, A. C., Shortt, B., Collon, M., \& Landgraf, B. (2015). Investigation of Photolithography Process on SPOs for the ATHENA Mission. In Proceedings of SPIE (Vol. 9603). [96030M ] SPIE - International Society for Optical Engineering. Proceedings of SPIE - The International Society for Optical Engineering https://doi.org/10.1117/12.2186810

\section{General rights}

Copyright and moral rights for the publications made accessible in the public portal are retained by the authors and/or other copyright owners and it is a condition of accessing publications that users recognise and abide by the legal requirements associated with these rights.

- Users may download and print one copy of any publication from the public portal for the purpose of private study or research.

- You may not further distribute the material or use it for any profit-making activity or commercial gain

- You may freely distribute the URL identifying the publication in the public portal 


\title{
Investigation of Photolithography Process on SPOs for the ATHENA Mission
}

\author{
S. Massahi ${ }^{a}$, D.A. Girou ${ }^{a}$, D.D.M. Ferreira ${ }^{a}$, F.E. Christensen ${ }^{a}$, A.C. Jakobsen ${ }^{a}$, B. Shortt ${ }^{b}$, \\ M. Collon ${ }^{c}$ and B. Landgraf ${ }^{c}$ \\ ${ }^{a}$ NSI, Elektrovej 327, Kgs. Lyngby, Denmark; \\ ${ }^{b}$ ESTEC, Keplerlaan 1, Noordwijk, The Netherlands; \\ ${ }^{c}$ COSINE, J.H.Oortweg 19, Leiden, The Netherlands;
}

\begin{abstract}
As part of the ongoing effort to optimize the throughput of the Athena optics we have produced mirrors with a state-of-the-art cleaning process. We report on the studies related to the importance of the photolithographic process. Pre-coating characterization of the mirrors has shown and still shows photoresist remnants on the $\mathrm{SiO}_{2}$ rib bonding zones, which influences the quality of the metallic coating and ultimately the mirror performance. The size of the photoresist remnants is on the order of $10 \mathrm{~nm}$ which is about half the thickness of final metallic coating.

An improved photoresist process has been developed including cleaning with $\mathrm{O}_{2}$ plasma in order to remove the remaining photoresist remnants prior to coating. Surface roughness results indicate that the $\mathrm{SiO}_{2}$-rib bonding zones are as clean as before the photolithography process is performed.
\end{abstract}

Keywords: Athena, Silicon Pore Optics (SPO), AFM, SEM, Photoresist, Surface Roughness, Photolithography Process, $\mathrm{O}_{2}$ Plasma, Stacking

\section{INTRODUCTION}

The Advanced Telescope for High Energy Astrophysics (Athena), has been selected as the second Large Mission of the European Space Agency's Cosmic Vision Science Programme, future X-ray Space telescope mission. ${ }^{1}$ Athena is a next-generation X-ray space observatory designed to study the hot, million-degree universe (e.g. supermassive black holes, evolution of galaxies and large-scale structures and matter under extreme conditions). The observatory concept is based on novel telescope optics - Silicon Pore Optics (SPO), with the focal plane instrumentation consisting of a Wide Field Imager (WFI) and Cryogenic X-ray Spectrometer (X-ray Integral Field Unit (X-IFU)).

The telescope is likely to consist of $\sim 120,000$ specially designed mirror plates arranged into SPO mirror modules. $^{2}$

The development of SPO has been ongoing for more than a decade with early efforts focused on demonstrating the basic principle, manufacturing steps and potential for use in space. ${ }^{3}$ The confirmation of the second Large Mission theme as the hot and energetic Universe and the subsequent selection of Athena, has allowing the technology development to become more focused through the consolidation of requirements. Current technology developments are focused on the angular resolution performance, mirror integration approach demonstration, environmental ruggedness and the mirror plate production process.

The process scheme from a $300 \mathrm{~mm}$ silicon wafer to a stack of SPO comprising a mirror module is illustrated in fig. 1. Prior to the metallic deposition, the mirror plates are oxidized (2, fig. 1), diced (3, fig. 1), ribbed (4, fig. 1 ), wedged (5, fig. 1), and have undergone a photolithography process (6, fig. 1$)$. These steps are prerequisite for the silicon-to-silicon bonding of the plates into mirror modules. The angular wedge consists of a thermally grown $\mathrm{SiO}_{2}$-layer on both sides of the plate, with a linearly graded thickness over the mirror plate. The backside of the SPO is ribbed in order to produce the pores through which the X-rays propagate with the ribs serving as

Further author information: (Send correspondence to S. Massahi)

S. Massahi: E-mail: sonmas@space.dtu.dk, Telephone: +4531241456

Optics for EUV, X-Ray, and Gamma-Ray Astronomy VII, edited by Stephen L. O'Dell, Giovanni Pareschi, Proc. of SPIE Vol. 9603, 96030M - (c) 2015 SPIE · CCC code: 0277-786X/15/\$18 · doi: 10.1117/12.2186810 
the mechanical interface (bond) between adjacent plates. The size of the mirror plates investigated in this paper is $65.7 \times 65.7 \times 0.775 \mathrm{~mm}^{3}$.

In the photolithography process, the top-side of the mirror plate is covered with a film-layer referred to as photoresist. The photoresist layer is spray-coated onto the SPO, which provides a uniform thickness of the film. An identical pattern in relation to the ribbed backside is produced in the film with a mask and UV-light, providing a top-surface pattern of $\mathrm{SiO}_{2}$ and photoresist.

The goal of the activity reported in this paper, is to identify the optimal and cleanest photolithography process performed on the mirrors, such that the surface roughness and reflectivity meet the requirements (angular resolution of 5 " HEW at $<7 \mathrm{keV})$.

1.

Super polished silicon

2.

Oxidation

3.

Dicing

4. Ribbing

5.

Wedging

6.

Photo-

lithography
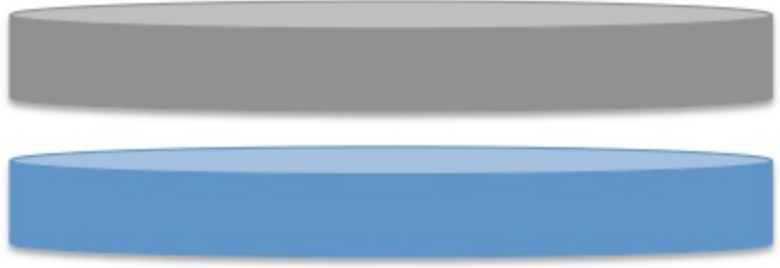

Top view

Side view
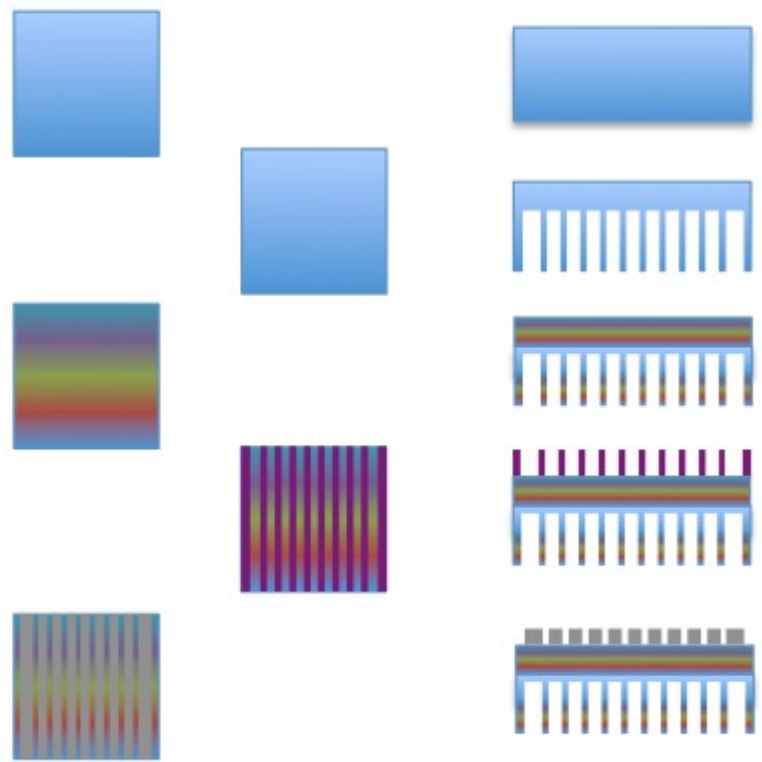

7.

Metallic deposition

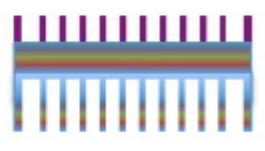

8.

\section{Stacking}

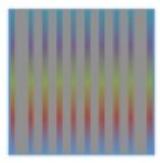

Figure 1. Process scheme of the production of an SPO mirror plate and mirror stack. 1. 300 mm Silicon wafer is prepared for oxidation. 2. An oxide layer is grown on the Silicon wafer. 3. The $300 \mathrm{~mm}$ wafer is diced into squares. 4. The plates are ribbed on the backside. 5. A linearly graded wedge is etched in the oxide layer. 6. A photolithography process (photoresist spraycoating, patterning exposure and development) is performed on the wafer. 7. Metal deposition, cleaning and lift-off. 8. The SPOs are bonded into a stack. 


\section{PRE-COATING CHARACTERIZATION OF THE MIRRORS}

A pre-coating characterization of SPO mirror plates processed up to step six (figure 1) has been performed. The purpose of the pre-coating characterization is that photoresist remnants have previously been observed on the area where the metallic coating has to remain on the mirrors i.e. the X-ray reflecting stripes of the mirror plate. This was first discussed in a previous publication. ${ }^{4,5}$ An AFM (Atomic Force Microscope) was found to be the most useful tool in terms of characterizing the photoresist remnants. Furthermore a SEM (Scanning Electron Microscope) was used to characterize the photoresist stripes on a larger scale.

The AFM instrument used was a Bruker AFM Icon. The instrument has a xy scanning range up to $90 \mu \mathrm{m}^{2}$. Two scanning areas were used in this study; $1 \mathrm{x} 1 \mu \mathrm{m}^{2}$ and $10 \mathrm{x} 10 \mu \mathrm{m}^{2}$. The noisefloor of the AFM is as low as $30 \mathrm{pm}$ which makes it possible to produce subnanometer measurements. The AFM probe used for the measurements is SCANASYST-AIR with a tip-radius lower than $12 \mathrm{~nm}$ which was used in Peak Force mode. ${ }^{6}$

Three spots were chosen for each mirror plate characterized by AFM, as indicated in figure 2. These spots are chosen to lie inbetween the photoresist stripes i.e. the $\mathrm{SiO}_{2}$ stripes which will ultimately be the $\mathrm{Ir} / \mathrm{B} 4 \mathrm{C}$ coated reflecting surfaces.
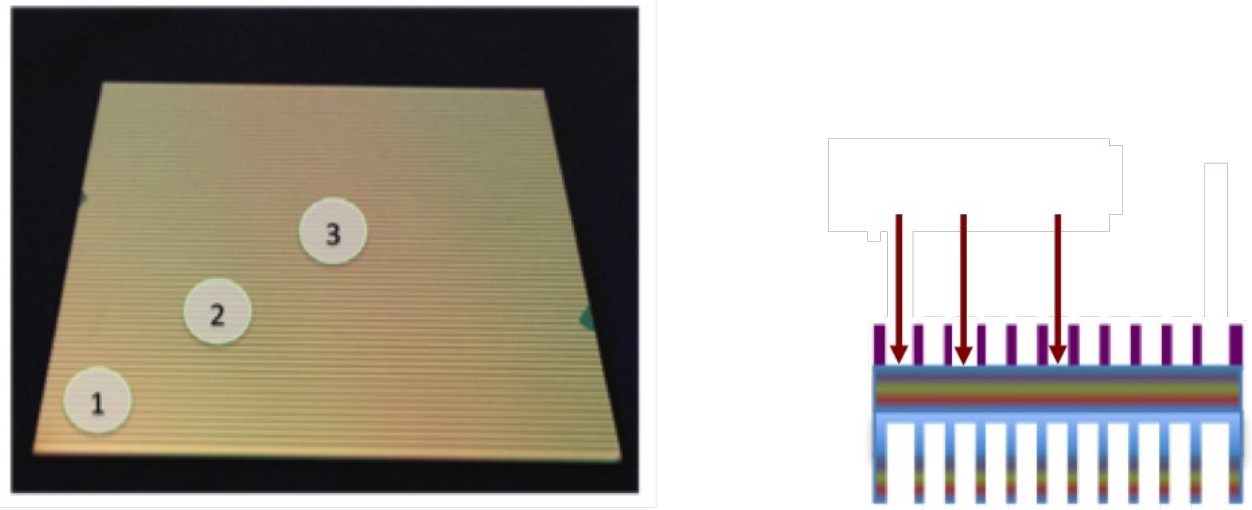

Figure 2. Indication of the 3 AFM scanning spots on the SPO mirror plate. The right image shows that the measurements are performed on the $\mathrm{SiO}_{2}$ layer inbetween the photoresist stripes.

Fig. 2, shows an SPO with 3 indicated spots, each representing a scanning area of spot 1,2 and 3. Three spots were chosen in all the measurements, which provides good statistics of the overall morphology of the plates. A typical set of SPO mirror plate images produced with the SEM is illustrated in fig. 3. The right image shows the smooth edge of the photoresist (thinner darker stripes) after the development process (step 6).
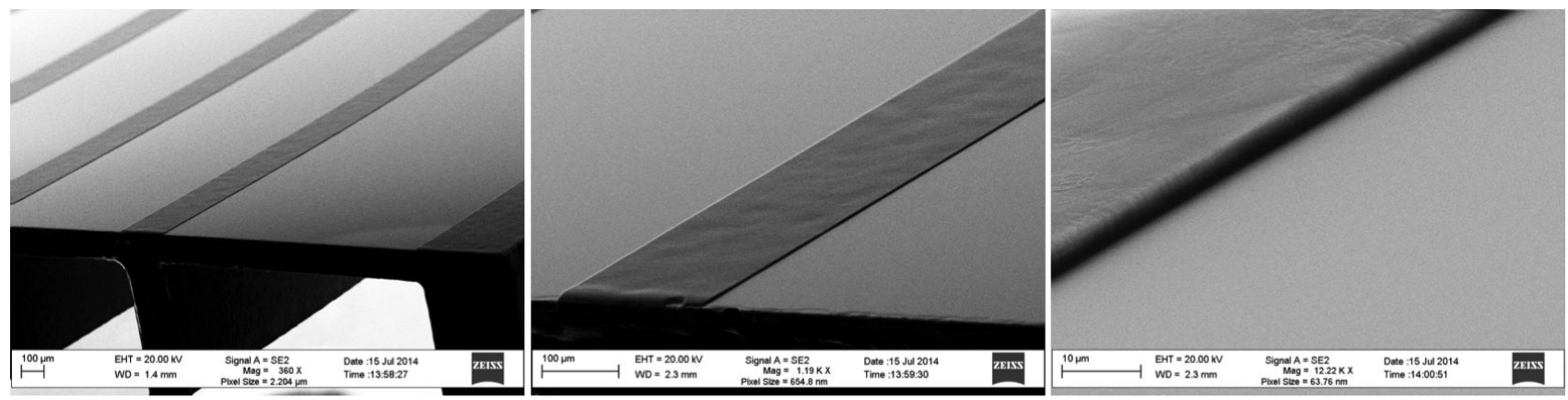

Figure 3. Images produced with a SEM. The photoresist is indicated by the dark-grey areas and the light-grey areas indicate the $\mathrm{SiO}_{2}$ layer. 
The two top rows in figure 4 show AFM measurements of a plate that has undergone the ribbing process (up to process step 5). This is before the photolithography process and as the images indicate the $\mathrm{SiO}_{2}$ surface is clean. The two lower rows in fig. 4, show images of a substrate that has undergone the current baseline spray-coated photoresist deposition process (up to process step 6). There is a clear indication of photoresist remnants on the surface both on small and large scale. The height of the tallest remnant is $\sim 10 \mathrm{~nm}$, which is $\sim 53 \%$ of the total thickness of the $\mathrm{Ir} / \mathrm{B}_{4} \mathrm{C}$ baseline coating. ${ }^{7,8}$ This affects the geometry of the metallic coating and can even produce holes in the coating after the lift-off process.
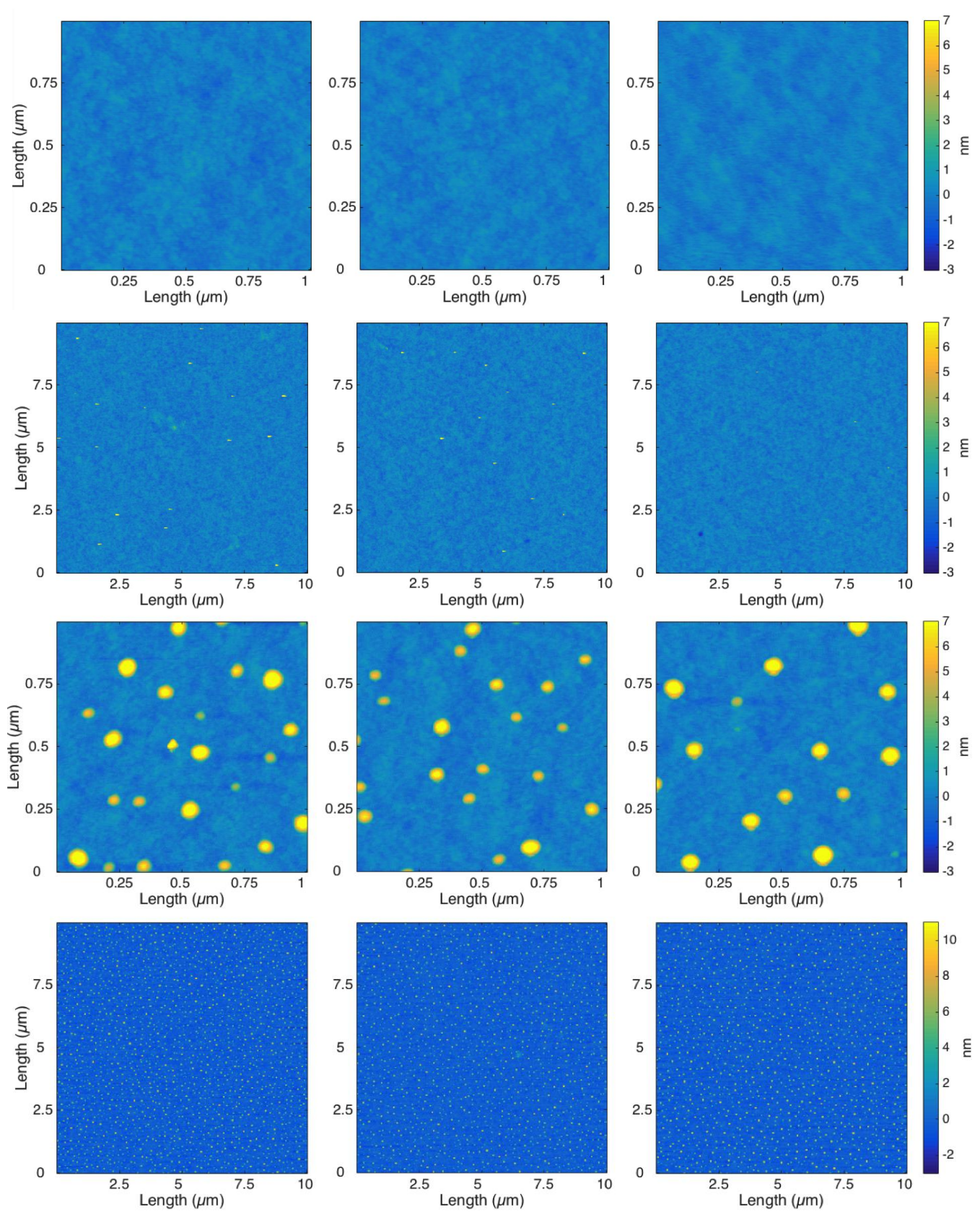

Figure 4. AFM measurements performed on $\mathrm{SiO}_{2}$. The two upper rows show the $\mathrm{SiO}_{2}$ layer before the photolithography process. The two lower rows show the $\mathrm{SiO}_{2}$ layer after the development process. The scanning area is $1 \mathrm{x} 1 \mu \mathrm{m}^{2}$ for the first and third row and $10 \times 10 \mu \mathrm{m}^{2}$ for the second and fourth row. Spot 1 is the left column, spot 2 is the center column and spot 3 is the right column. 


\section{OPTIMIZATION OF THE PHOTOLITHOGRAPHY PROCESS}

Based on previous investigations, ${ }^{4}$ reconfirmed through the results of the pre-coating characterization as described in section 2, an effort to optimize the steps in the photolithography process (step 6) leading to a cleaner $\mathrm{SiO}_{2}$ surface has been made. The photolithography process studies have been performed at DTU Danchip, which is the Danish national center for micro- and nanofabrication. The process scheme, which utilizes spin coating, is shown in fig. 5 and a short description of each step is given below;

Step 6.1 Hexamethyldisilazane (HMDS) treatment, which increases the adhesion of the photoresist to the $\mathrm{SiO}_{2}$ surface. HMDS is introduced into the chamber, where the wafer is placed, as a vapor. This produces a layer of hydrophilic molecules on top of the hydrophobic surface $\left(\mathrm{SiO}_{2}\right)$, which easily bonds with the photoresist $^{9}$

Step 6.2 Photoresist deposition via spin coating, the thickness of the deposited resist layer was measured to be $\sim 9 \mu \mathrm{m}$. The photoresist applied is a negative photoresist called nLOF 2070. After the deposition of photoresist the wafer is soft baked on a hotplate (this removes solvents in the resist)

Step 6.3 UV-exposure, the exposed areas become more dismissive for the developing chemical. This applies for a negative resist as the one used in the spin-coating process. For a positive resist which is the one used for the spray-coating process, the opposite applies. After the UV-exposure the wafer is post baked on a hot plate (this cross-links the polymers in the resist)

Step 6.4 Development, a special chemical removes the unexposed areas of the photoresist

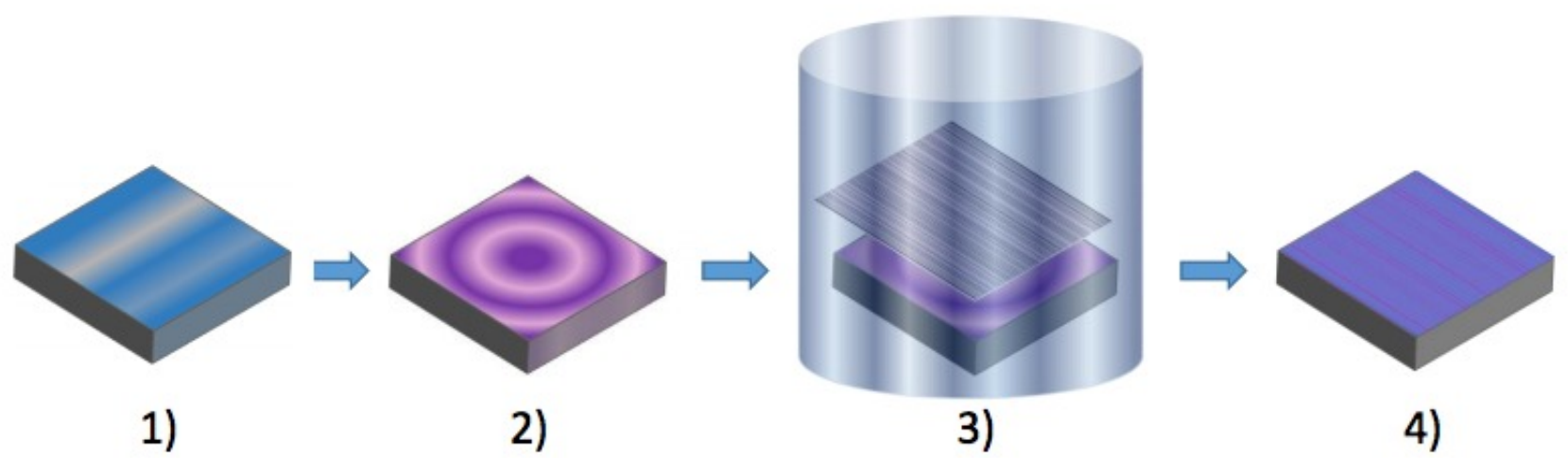

Figure 5. Photolithography process steps. 1) HMDS on SPO. 2) Photoresist deposition of nLOF 2070 via spin coating. 3) UV-exposure of the substrate with a mask. 4) Development of the UV-exposed areas.

Following implementation of the described process, it was discovered that enhanced cleanliness of the process was achievable within the development process step (step 6.4). The chemical used to dissolve the unexposed photoresist has a particular importance. The chemical used for the initial process study was AZ 726 MIF (a solution of 2.38\% tetra Methyl Ammonium Hydroxide). This developer showed a similar photoresist remnant pattern as the spray-coated plates (figure 4, (bottom two rows)), see figure 6 (top two rows).

From an investigation of the datasheet for the AZ 726 MIF developer, an alternative developer, AZ 826 MIF, with added surfactant, was identified. This developer was considered interesting as the added surfactant and additives should yield a cleaner and scum-free development.

The photolithography process was repeated multiple times using the AZ 826 MIF developer with the results being shown in fig. 6 (lower two rows). A significant improvement in the cleanliness of the plates has been obtained. The improvement is quantified through surface roughness measurements which are presented in Section 5 .

Even though the residual photoresist on the surface was significantly reduced, it was decided to implement a further cleaning process in order to remove the remaining residuals. This cleaning process is described in the following section. 

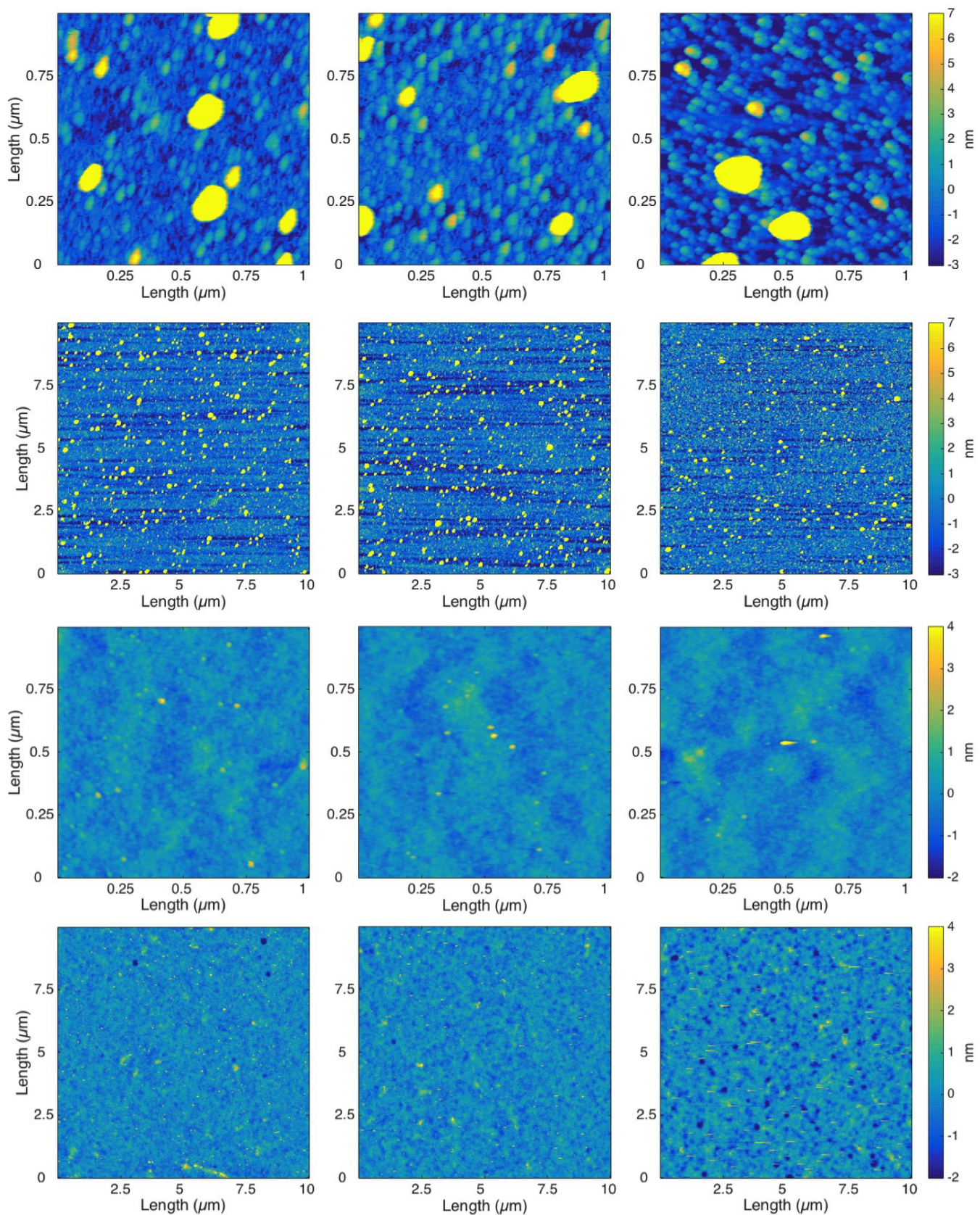

Figure 6. AFM measurements performed on $\mathrm{SiO}_{2}$ before metal deposition. Measurements have been performed after the development process. Development chemical AZ 726 MIF was used on the two top rows and AZ 826 MIF was used on the two lower rows. The scanning area is $1 \mathrm{x} 1 \mu \mathrm{m}^{2}$ for the first and third row and $10 \mathrm{x} 10 \mu \mathrm{m}^{2}$ for the second and fourth row. Spot 1 is the left column, spot 2 is the center column and spot 3 is the right column. The significant improvement achieved through the use of the surfactant enriched developer is clear. 


\section{4. $\mathrm{O}_{2}$ PLASMA CLEANING}

As stated in the previous section a cleaning method was investigated in order to remove the residuals remaining following the switch to the better performing developer. Initially, a wet chemical cleaning was under consideration, however such an etching method is likely to increase the surface roughness.

Alternatively, a dry cleaning process such as an $\mathrm{O}_{2}$ plasma cleaning can be used and is in fact usually recommended after a development process in order to remove scumming (water combined with photoresist). Therefore it was chosen to perform this cleaning process on the mirror plates. A low intensity $\mathrm{O}_{2}$ plasma clean was chosen so as not to remove the photoresist stripes required for step 7 of the overall SPO process i.e. metal deposition and lift-off.

The $\mathrm{O}_{2}$ plasma etching process removes amounts of photoresist in an isotropic way and was in this case used to clean the substrate surface after the photolithography process. The bombardment of Oxygen atoms on top of the substrate either carries away or reacts with the organic photoresist on the surface. The result of this reaction is $\mathrm{H}_{2} \mathrm{O}$ and $\mathrm{CO}_{2}$. The process takes place in a vacuum chamber located at Danchip with an extraction system, so the $\mathrm{H}_{2} \mathrm{O}$ and the $\mathrm{CO}_{2}$ are removed. An illustration of this process is shown in figure 7 .
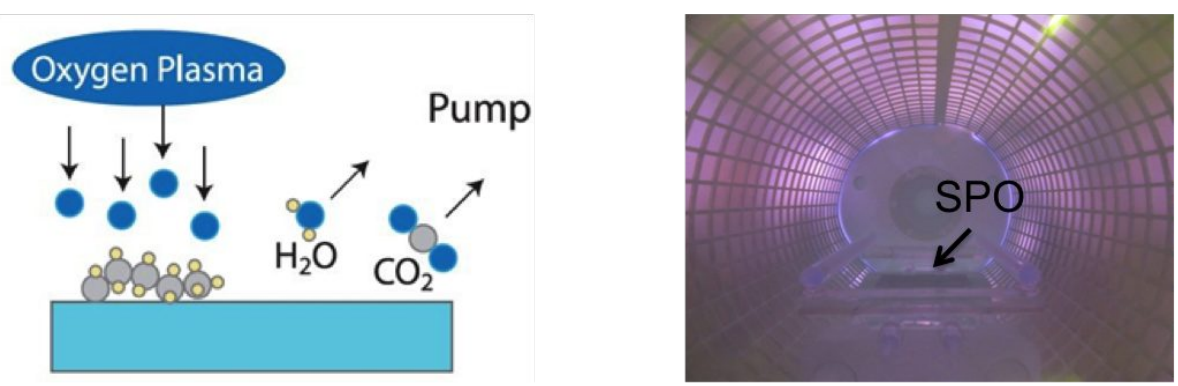

Figure 7. $\mathrm{O}_{2}$-plasma cleaning process. Left ionized Oxygen atoms are bombarded onto the sample, resulting in a reaction between the Oxygen and the organic material. Right actual image of a cleaning process at DTU of an SPO.

In order to determine the optimized O2-plasma cleaning process different intensities, gas inflows and durations were tested.

The intensity is directly related to the temperature of the chamber and at high intensities (power of $1000 \mathrm{~W}$ ) the temperature reaches as high as $110^{\circ} \mathrm{C}$. The high intensity affects the sidewalls of the photoresist, which changes the final pattern on the mirror. If the intensity is too low, the gasses do not ignite, resulting in no cleaning. Intensities between the two extremes were chosen. The process settings are shown in table 1.

The reason for a high start temperature for the wafer developed with AZ 726 MIF is that the chamber was used at a high intensity prior to this cleaning run. In general, the chamber is a room temperature at the start of a cleaning run, as seen for the two other experiments. In addition, the $\mathrm{O}_{2}$ flow rate $(400 \mathrm{sccm})$ was reduced to 200 $(\mathrm{sccm})$ in order to have a less intense process for the second and third runs.

\begin{tabular}{ccccccccc} 
Experiment & $\begin{array}{c}\text { Deposition } \\
\text { method }\end{array}$ & Developer Type & Inflow $\mathrm{O}_{2}$ & Inflow $\mathrm{N}_{2}$ & Power & Duration & $\mathrm{T}_{\text {start }}$ & $\mathrm{T}_{\text {max }}$ \\
\hline & & & $(\mathrm{sccm})$ & $(\mathrm{sccm})$ & $(\mathrm{W})$ & $(\mathrm{min})$ & $\left({ }^{\circ} \mathrm{C}\right)$ & $\left({ }^{\circ} \mathrm{C}\right)$ \\
\hline 1 & Spin & AZ 726 MIF & 400 & 70 & 150 & 20 & 46 & 51 \\
\hline 2 & Spin & AZ 826 MIF & 200 & 70 & 100 & 15 & 21 & 36 \\
\hline 3 & Spray & Fuji OPD 4262 & 200 & 70 & 100 & 30 & 23 & 36 \\
\hline
\end{tabular}

Table 1. Parameters for the 3 different $\mathrm{O}_{2}$ plasma cleaning process runs. The top two experiments utilize the optimized process as described in section 3. The bottom row (experiment 3) is an SPO mirror plate produced using the previously existing spray coating approach. 
The images produced with the AFM after the cleaning are illustrated in figures 8 and 9. Visually the two top rows (AZ $726 \mathrm{MIF}$ ) in fig. 8 look slightly cleaner than before cleaning (fig. 6) but the size and quantity of residuals are too large for the cleaning process to remove them. The two lower rows in fig. 8 are very clean. The small amount of photoresist that was left after development with AZ 826 MIF has successfully been removed and the mirror plate is prepared for coating. In addition to investigating the cleaning efficiency upon the mirror plates with spin coated resist (experiment 1 and 2) it was decided to also check the process effect upon a mirror plate with spray coated resist (experiment 3). It can be seen that the low intensity cleaning for 30 min on the spray-coated photoresist was not sufficient to remove the residuals with the images in fig. 9 being similar to the ones before cleaning (fig. 4).
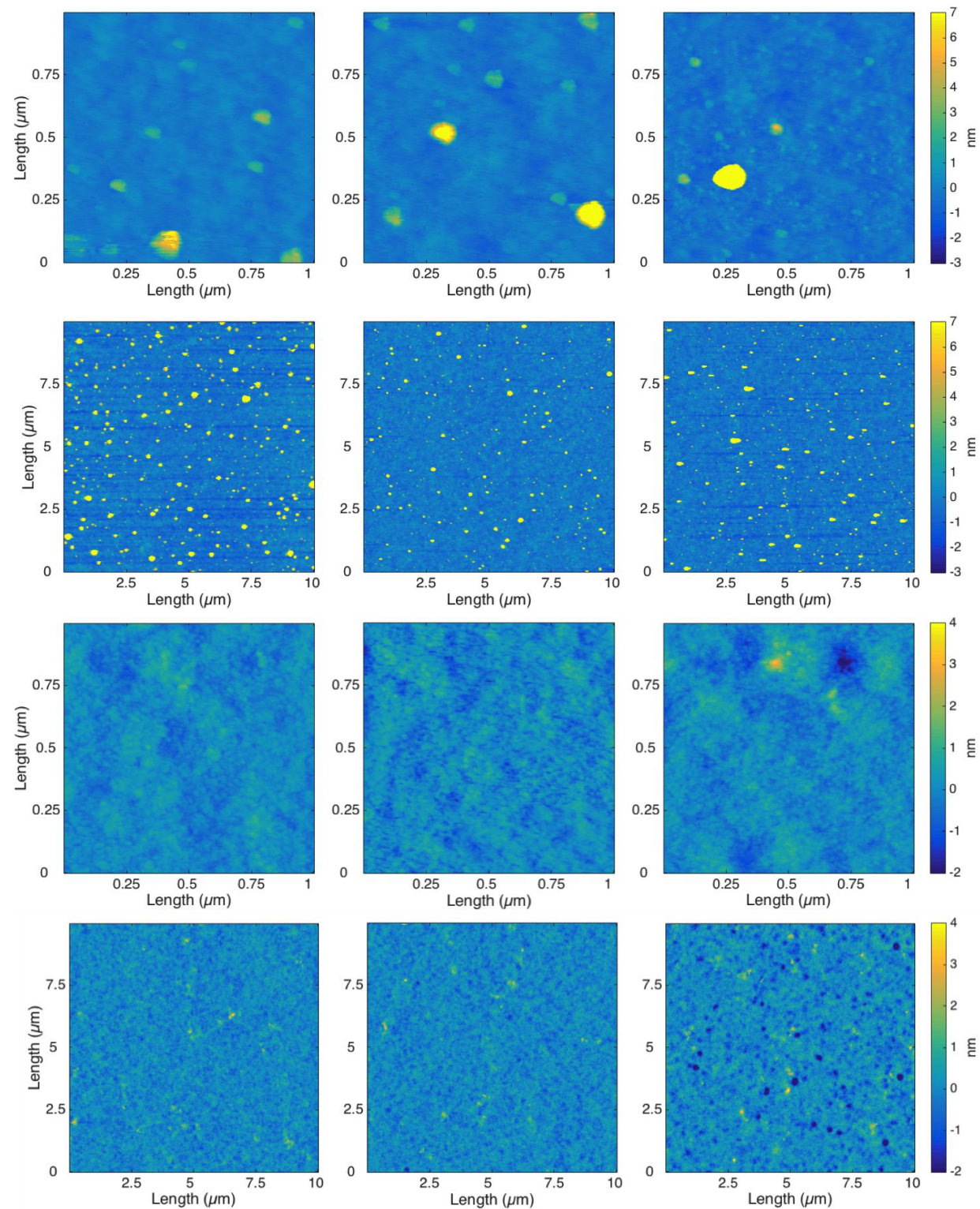

Figure 8. AFM measurements performed on $\mathrm{SiO}_{2}$ after an $\mathrm{O}_{2}$-plasma clean. Development chemical AZ 726 MIF was used on the two top rows and AZ 826 MIF was used on the two lower rows, both deposited via spin coating. The scanning area is $1 \mathrm{x} 1 \mu \mathrm{m}^{2}$ for the first and third row and $10 \mathrm{x} 10 \mu \mathrm{m}^{2}$ for the second and fourth row. Spot 1 is the left column, spot 2 is the center column and spot 3 is the right column. 

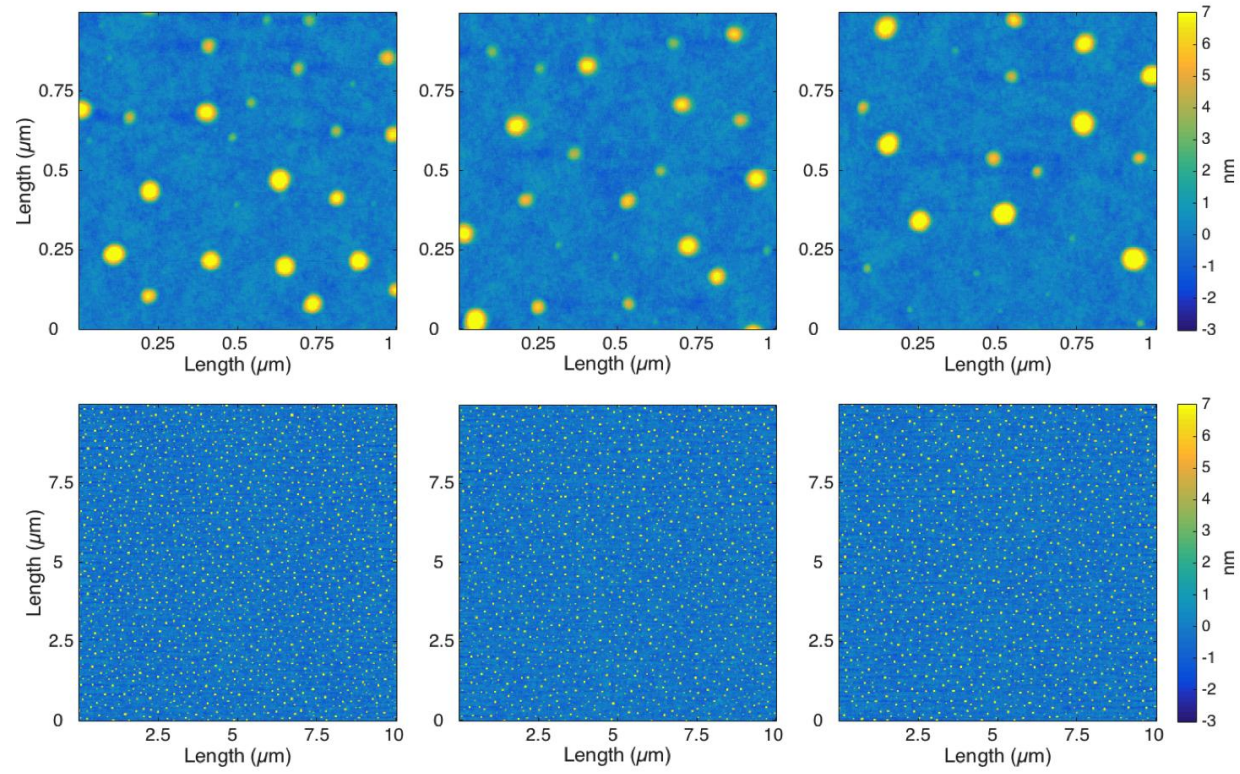

Figure 9. AFM measurements performed on $\mathrm{SiO}_{2}$ after an $\mathrm{O}_{2}$-plasma clean. Fuji OPD 4262 was the development chemical. The scanning area is $1 \mathrm{x} 1 \mu \mathrm{m}^{2}$ for the top and third row and $10 \mathrm{x} 10 \mu \mathrm{m}^{2}$ for the second and lower row. Spot 1 is the left column, spot 2 is the center column and spot 3 is the right column.

\section{SURFACE ROUGHNESS RESULTS}

In order to quantify the improvement due to the optimized photolithography process the surface roughness of the SPO mirror plates has been calculated from the AFM results. To extract the surface roughness $(\sigma)$ results the 1-dimensional power spectral density (1D-PSD) has been calculated.

The surface roughness of the SPOs are required to be low after the multilayer coating and lift-off, in order to achieve the reflectivity and image quality specifications essential for the ATHENA mission.

The software used to analyze the AFM measurements is called NanoScope. It has a built in 1D-PSD algorithm, which was used to calculate the surface roughness of the substrates.

Prior to the calculation of the surface roughness a third order line wise correction of the full image was performed. The third order polynomial calculates the least squares fit for each line in the image, which cancels the Z-offset between the scanning lines as well as the tilt and bow in each line. By filtering out the low frequency noise, the tilt and the bow in the data, a more accurate surface roughness is achieved.

The calculated surface roughness of the plates developed with AZ 726 MIF, AZ 826 MIF and the developer from Micronit are given in tables 2-4. The average SPO mirror plate surface roughness before the photolithography process is $0.31 \mathrm{~nm}$, given in table 2 . The only plate that has an average surface roughness below $0.5 \mathrm{~nm}$ is the one developed with AZ $826 \mathrm{MIF}$ and cleaned with a low intensity $\mathrm{O}_{2}$-plasma cleaning process (experiment 2 ). The value is $0.42 \mathrm{~nm}$.

This is a clear improvement from the other developer AZ 726 MIF (experiment 1), which resulted in a surface roughness average of a factor 10 higher and the developer Fuji OPD 4262 (experiment 3) which is a factor of 3 higher. 


\begin{tabular}{lcccc} 
Developer AZ 726 MIF & Spot 1 & Spot 2 & Spot 3 \\
\hline \hline & $\begin{array}{c}\text { Scan size } \\
(\mu \mathrm{m})\end{array}$ & $\begin{array}{c}\sigma \\
(\mathrm{nm})\end{array}$ & $\begin{array}{c}\sigma \\
(\mathrm{nm})\end{array}$ & $\begin{array}{c}\sigma \\
(\mathrm{nm})\end{array}$ \\
\hline Before photolithography & $1.00 \times 1.00$ & 0.28 & 0.26 & 0.27 \\
& $10.0 \times 10.0$ & 0.38 & 0.36 & 0.29 \\
\hline With resist & $1.00 \times 1.00$ & 4.47 & 3.79 & 6.80 \\
& $10.0 \times 10.0$ & 4.88 & 5.28 & 4.42 \\
\hline $\mathrm{O}_{2}$ clean for 20 min & $1.00 \times 1.00$ & 0.57 & 1.16 & 3.14 \\
& $10.0 \times 10.0$ & 1.89 & 1.31 & 2.30 \\
\hline \hline
\end{tabular}

Table 2. Table showing the $\sigma$-values of the SPO developed with AZ 726 MIF (experiment 1 ). The scanning areas are; 1 $\mu \mathrm{m} \times 1 \mu \mathrm{m}$ and $10 \mu \mathrm{m} \times 10 \mu \mathrm{m}$, of three different spots.

\begin{tabular}{lcccc} 
Developer AZ 826 MIF & Spot 1 & Spot 2 & Spot 3 \\
\hline \hline & $\begin{array}{c}\text { Scan size } \\
(\mu \mathrm{m})\end{array}$ & $\begin{array}{c}\sigma \\
(\mathrm{nm})\end{array}$ & $\begin{array}{c}\sigma \\
(\mathrm{nm})\end{array}$ & $\begin{array}{c}\sigma \\
(\mathrm{nm})\end{array}$ \\
\hline With resist & $1.00 \times 1.00$ & 0.37 & 0.36 & 0.41 \\
& $10.0 \times 10.0$ & 0.53 & 0.49 & 0.65 \\
\hline O $_{2}$-clean for 15 min & $1.00 \times 1.00$ & 0.32 & 0.40 & 0.44 \\
& $10.0 \times 10.0$ & 0.38 & 0.39 & 0.56 \\
\hline \hline
\end{tabular}

Table 3. Table showing the $\sigma$-values of the SPO developed with AZ 826 MIF (experiment 2). The scanning areas are; 1 $\mu \mathrm{m} \times 1 \mu \mathrm{m}$ and $10 \mu \mathrm{m} \times 10 \mu \mathrm{m}$, of three different spots.

\begin{tabular}{lcccc} 
Developer Fuji OPD 4262 & & Spot 1 & Spot 2 & Spot 3 \\
\hline \hline & $\begin{array}{c}\text { Scan size } \\
(\mu \mathrm{m})\end{array}$ & $\begin{array}{c}\sigma \\
(\mathrm{nm})\end{array}$ & $\begin{array}{c}\sigma \\
(\mathrm{nm})\end{array}$ & $\begin{array}{c}\sigma \\
(\mathrm{nm})\end{array}$ \\
\hline With resist & $1.00 \times 1.00$ & 1.39 & 1.02 & 1.32 \\
& $10.0 \times 10.0$ & 1.30 & 1.14 & 1.29 \\
\hline $\mathrm{O}_{2}$ clean for 30 min & $1.00 \times 1.00$ & 1.17 & 1.06 & 1.26 \\
& $10.0 \times 10.0$ & 1.30 & 1.20 & 1.27 \\
\hline \hline
\end{tabular}

Table 4. Table showing the $\sigma$-values of the SPO developed with Fuji OPD 4262 (experiment 3). The scanning areas are; $1 \mu \mathrm{m} \times 1 \mu \mathrm{m}$ and $10 \mu \mathrm{m} \times 10 \mu \mathrm{m}$, of three different spots.

\section{SUMMARY}

We have reported on the production of a Silicon Pore Optic and qualified the wafers prior metallic coating process. A pre-characterization of the plates after a spray-coated photoresist deposition indicates that photoresist remnants $(\sim 10 \mathrm{~nm}$ thick) are located on the X-ray reflective surface. The small photoresist remnants have a large impact on the final geometry of the metallic coating and hereby the overall performance of the X-ray optics for the Athena mission.

We have developed a spin-coating photoresist process and located that the cleanliness of the Silicon Pore Optics can be improved in the development step by changing the developing chemical (AZ $826 \mathrm{MIF}$ ). The AZ 826 MIF dissolves photoresist and contains additives that remove photoresist residuals to a certain extend. The photoresist remnants are still observed but with a large reduction in size.

Furthermore we have implemented a cleaning step consisting of a dry Oxygen plasma process that has proven to remove the very small-scale $(\sim 3 \mathrm{~nm}$ thick) photoresist remnants at a low intensity (power of $100 \mathrm{~W})$ that are still present after the development process. 
The characterization of the photoresist remnants has been performed with an Atomic Force Microscope. The surface roughness, related to the morphology of the surface, has been derived in a software called NanoScope and been used to compare the wafers after development and cleaning with different development chemicals. The lowest surface roughness was observed with the AZ $826 \mathrm{MIF}$ developer type to be in the order of $0.4 \mathrm{~nm}$ compared to the wafer surface roughness prior the photoresist process $(\sigma=0.3 \mathrm{~nm})$. The spray-coated photoresist developed with Fuji OPD 4262 showed an average surface roughness of $1.2 \mathrm{~nm}$.

The AZ 826 MIF will be tested in the spray-coating photoresist process instead of the Fuji OPD 4262 to examine if the same results are perceived as for the spin-coating process.

\section{ACKNOWLEDGMENTS}

We would like to thank DTU Danchip for providing us with their facilities and their knowledge. Especially, A. M. Jørgensen for helping designing the photoresist project and T. A. Anhøj for sharing his knowledge about photoresist processes in general.

This activity has been funded by the European Space Agency under contract 4000102248/12/NL/PM.

\section{REFERENCES}

1. "ESA, Cosmic vision-Athena." http://sci.esa.int/cosmic-vision/54517-athena/.

2. R. Willingale, G. Pareschi, F. E. Christensen, and J. W. Herder, "The hot and energetic universe: The optical design of the athena+ mirror," p. 14, 2013.

3. M. Bavdaz, D. Lumb, A. Peacock, M. Beijersbergen, and S. Kraft, "Development of x-ray optics for the xeus mission," DESIGN AND MICROFABRICATION OF NOVEL X-RAY OPTICS II, pp. 95-103, 2004.

4. D. D. M. Ferreira, A. C. Jakobsen, F. E. Christensen, B. Shortt, M. Krumrey, J. Garnaes, and R. B. Simonsen, "Development and characterization of coatings on silicon pore optics substrates for the athena mission," Proceedings of the SPIE - the International Society for Optical Engineering 8443, p. 84435E, 2012.

5. A. C. Jakobsen, D. D. M. Ferreira, F. E. Christensen, B. S., M. Collon, and M. D. Ackermann, "Preliminary coating design and coating developments for athena," Proceedings of SPIE-the international society for optical engineering , 2011.

6. S. B. Kaemmer, "Introduction to bruker's scanasyst and peakforce tapping afm technology," p. 12, 2011.

7. D. D. M. Ferreira, F. E. Christensen, A. C. Jakobsen, N. J. Westergaard, and B. Shortt, "Athena optimized coating design," Proceedings of Spie, the International Society for Optical Engineering, Progress in Biomedical Optics and Imaging, Progress in Biomedical Optics and Imaging 8443, 2012.

8. D. D. M. Ferreira, F. E. Christensen, A. C. Jakobsen, N. J. S. Westergaard, and B. Shortt, "Coating optimization for the athena+ mission," Proceedings of SPIE, the International Society for Optical Engineering , 2013.

9. J. Plummer, M. Deal, and P. Griffin, Silicon VLSI technology : fundamentals, practice and modeling, Prentice Hall, 2000. 